\title{
Changes in left ventricular function during exercise and their relation to ST segment changes in patients with angina
}

\author{
MARTIN J O'HARA, * RODERICK I JONES, AVIJIT LAHIRI, EDWARD B \\ RAFTERY
}

From the Department of Cardiology, and the Division of Clinical Sciences, Northwick Park Hospital and Clinical Research Centre, Harrow, Middlesex

SUMMARY The high count sensitivity of the non-imaging nuclear probe affords the possibility of measuring left ventricular ejection fraction continuously during short term interventions. The nuclear probe was used to examine the pattern of change of left ventricular function during dynamic exercise and its temporal relation to ST segment depression in 12 patients with stable exertional angina. After in vivo blood pool labelling with technetium- $99 \mathrm{~m}$ the left ventricular time-activity waveform was detected by the nuclear probe and was continuously recorded on a strip chart. The 15 beat mean ejection fraction and the ST segment level $80 \mathrm{~ms}$ after the J point were measured at rest and every 30 seconds during maximal ergometric exercise and during recovery. The mean ejection fraction was 54.3\% (range 46-64\%) at rest and fell during exercise in all subjects by a mean of $16.8 \%$ (range 6-25\%). In contrast, in a control group of 16 healthy male volunteers the mean ejection fraction was $55.9 \%$ (range $47-64 \%$ ) at rest and increased in all by a mean of $10 \cdot 2 \%$ (range $3-19 \%$ ) during exercise. The difference of ejection fraction response to exercise between the patients and controls was due to pronounced increases in relative end diastolic and especially end systolic volumes in the patients. Relative stroke volume differed between patients and controls only at peak exercise. ST segment depression $>1 \mathrm{~mm}$ developed in 11 of the 12 patients. A decrease of $>5 \%$ in ejection fraction occurred within 1 minute of starting exercise in nine of the 12, and in 11 patients it preceded the beginning of ST depression. In most of this selected group of patients the ejection fraction had fallen during exercise before the appearance of ischaemic electrocardiographic changes.

Invasive studies in animals indicate that myocardial ischaemia produces impairment of left ventricular function that can be detected before the appearance of ischaemic changes in the electrocardiogram. ${ }^{1-3}$ Non-invasive studies in man with gated equilibrium blood pool methods ${ }^{4-6}$ and serial first-pass gold$195 \mathrm{~m}$ angiography ${ }^{7}$ have confirmed that an abnormal response of the ejection fraction to exercise is a sensitive indicator of coronary heart disease and its outcome. $^{8}$ These methods suffer from the disadvantage of a slow response-time, making precise temporal correlations difficult. The non-imaging nuclear

Requests for reprints to Dr E B Raftery, Cardiology Department, Northwick Park Hospital, Harrow, Middlesex HA1 3UJ.

^Present address: St Vincents Hospital, Dublin 4, Ireland.

Accepted for publication 30 September 1985 probe used in the beat to beat mode permits the rapid detection of changes in left ventricular function ${ }^{9}$ and can be used continuously during exercise and other interventions. ${ }^{1011}$

We have used this technique to examine the temporal relation between the onset of left ventricular dysfunction and the appearance of electrocardiographic evidence of myocardial ischaemia during dynamic exercise in patients with stable angina pectoris due to documented obstructive coronary artery disease.

\section{Patients and methods}

We studied 12 patients ( 10 male, 2 female), mean age 63.2 years (range 50-71), with stable angina pectoris that was reproducible on repeated treadmill testing and was associated with ischaemic ST segment de- 
pression. Coronary artery disease was documented by selective arteriography within 30 days of the study in all cases: three patients had single vessel, three had two vessel, and six had three vessel disease. Two had a documented previous myocardial infarction; angina pectoris had been present for a mean of 25.3 (range 6-48) months. Antianginal medication before the study consisted of a calcium ion antagonist in seven patients, long acting nitrate in three, and a beta blocker in two.

Previous antianginal medication was withdrawn gradually, long acting nitrates over at least $\mathbf{4 8}$ hours and other drugs over at least 14 days. The patients rested semi-supine for $\mathbf{3 0}$ minutes before the study. During this time the blood pool was labelled by means of stannous pyrophosphate and technetium$99 \mathrm{~m}(740 \mathrm{MBq})$. Thyroid uptake of technetium was blocked by parenteral sodium perchlorate $(200 \mathrm{mg})$.

The patients performed graded exercise on a reclining cycle in the $25^{\circ}$ semisupine position on a specially constructed ergometer. After they had started to cycle against zero resistance the workload was gradually increased over 15 seconds to 150 kilopond metres per minute ( $25 \mathrm{~W})(\mathrm{kpm} / \mathrm{min})$. This was to minimise the initial isometric component of exercise. The workload was gradually increased every
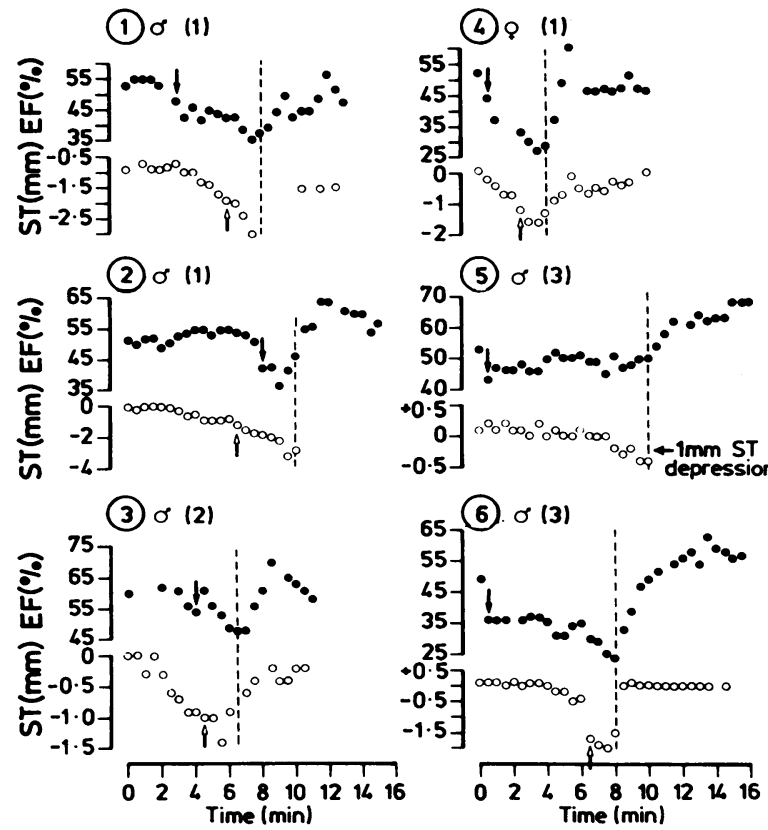

Fig. 1 Left ventricular ejection fraction (EF) in per cent (closed circles) and $S T$ segment level in mm (open circles) in 12 patients at 30 second intervals during maximal exercise and during recovery. Some data points are missing for technical reasons. Patients' study number, sex, and the number of angiographically diseased coronary vessels are indicated. The vertical interrupted line in each graph represents the end of exercise. The closed arrows indicate the time of onset of a $5 \%$ (absolute) fall in ejection fraction. The open arrows indicate the time at which $1 \mathrm{~mm} S T$ depression developed relative to electrocardiogram at rest. three minutes by $150 \mathrm{kpm} / \mathrm{min}(25 \mathrm{~W})$ and exercise was continued until symptoms appeared.

\section{LEFT VENTRICULAR FUNCTION MEASUREMENT}

We used the non-imaging nuclear probe (Nuclear Stethoscope, Bios Inc.) to detect left ventricular time-activity and we established the left ventricular and background regions of interest by means of operating algorithms and techniques described elsewhere. ${ }^{1213}$ These regions of interest were marked on the chest surface with ink and the position of the probe was maintained by hand throughout the study.

The unprocessed signal from the scintillation detector was also fed directly (bypassing the Nuclear Stethoscope's computer) to a signal filter which reduced artefact (but did not distort the peaks and troughs of the waveform) and thence to a Watanabe strip-chart recorder with paper running at $100 \mathrm{~mm}$ per minute. A record of each study was also stored on magnetic tape.

We used a ruler to draw a line through the mean background counts, and the end diastolic counts were measured by hand from this line. The ejection fraction (calculated as the mean stroke counts divided by the mean end diastolic counts over the last 15 beats of each 30 second interval) was measured
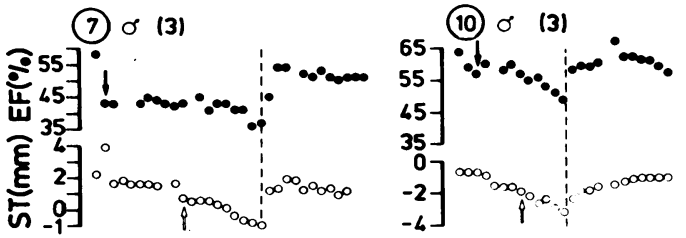

\section{(8) $\circ(2)$}

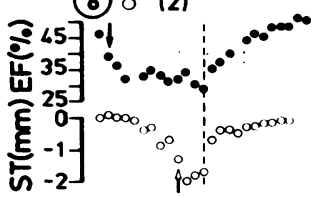

(11) $8 \quad(3)$

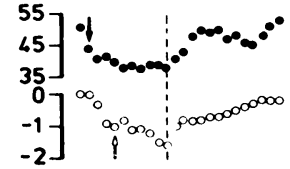

(9) $\circ$ (1)

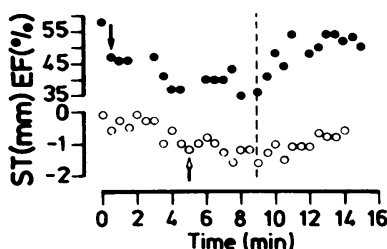


immediately before, during, and for five to six minutes after exercise. Extrasystoles and cycles immediately after an extrasystole were rejected. Background was corrected during the third minute of the first stage of exercise and the third minute of recovery.

Bipolar electrocardiographic leads CM5 and CC5 were recorded on a Marquette three channel recorder and ST segment displacement was measured $80 \mathrm{~ms}$ after the $\mathrm{J}$ point, in whichever lead showed the greatest degree of ST depression. The ST level was measured to an accuracy of $0.1 \mathrm{~mm}$ from the stable isoelectric baseline connecting successive PR intervals. The mean figure for three consecutive beats was measured every $30 \mathrm{~s}$.

\section{CONTROL SUBJECTS}

We also studied 16 male volunteers (mean age 37.6 years, range 27-44). None had a history suggestive of cardiovascular disease and all had a normal electrocardiogram both at rest and on maximal treadmill exercise. They followed the same exercise protocol as the patients and the ejection fraction was measured every $60 \mathrm{~s}$.

\section{Results}

The symptoms causing patients to stop exercising were angina in 10 and dyspnoea and fatigue in one each. The patients' mean exercise time was 7.5

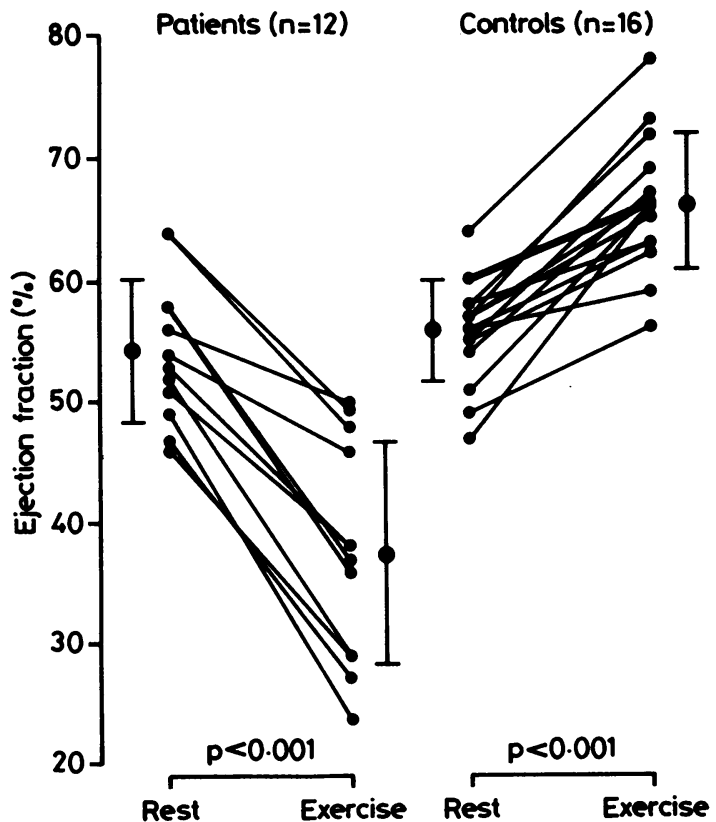

Fig. 2 Individual ejection fraction values for the controls and the patients at rest and at peak exercise.

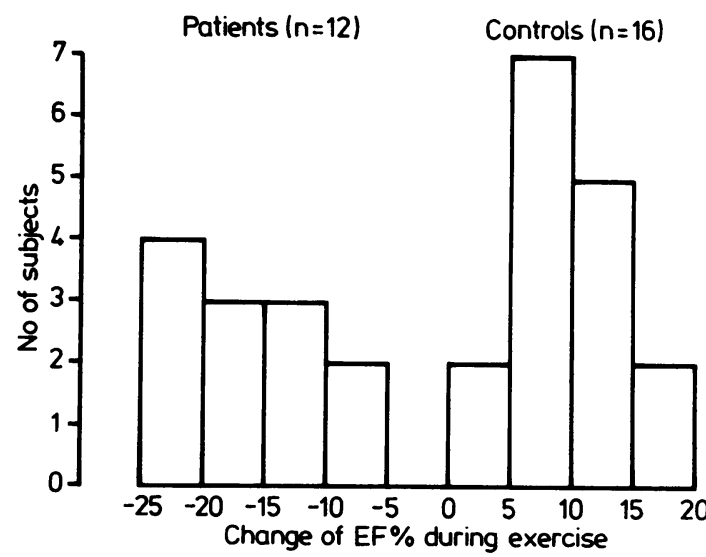

Fig. 3 Percentage change in left ventricular ejection fraction during exercise in 12 patients and 16 normal controls.

minutes (range 4.0-10.5) and the workloads achieved were $300 \mathrm{kpm} / \mathrm{min}(50 \mathrm{~W})$ in five, $450 \mathrm{kpm} / \mathrm{min}(75$ W) in six, and $600 \mathrm{kpm} / \mathrm{min}(100 \mathrm{~W})$ in one. All but one patient developed ST segment depression of $>1 \mathrm{~mm}$ relative to the resting value (mean $-1.8 \mathrm{~mm}$, range -0.6 to $-3 \cdot 2)$. All the control subjects reached a workload of $450 \mathrm{kpm} / \mathrm{min}(75 \mathrm{~W})$ and five achieved $600 \mathrm{kpm} / \mathrm{min}(100 \mathrm{~W})$. All stopped exercise because of fatigue, and none developed ST segment depression. Some of the ST segment data during recovery were lost for three patients (cases 1,2 , and 5 in Fig. 1) for technical reasons. The individual

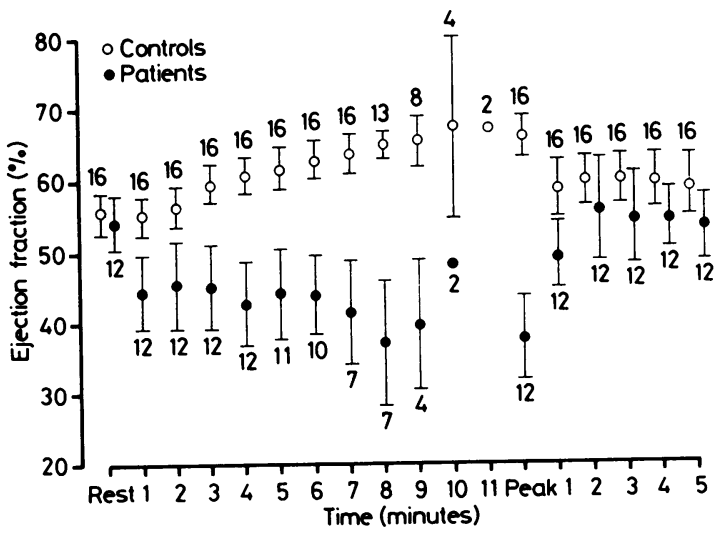

Fig. 4 Mean left ventricular ejection fraction in patients (closed circles) and controls (open circles) at rest and at each minute during exercise and recovery. Vertical bars represent $95 \%$ confidence intervals and the adjoining numbers indicate the number of observations contributing to each data point. Fewer patients than normal subjects attained the higher workloads. Peak values include different workloads. Statistically significant divergence between patients and normal subjects occurred within one minute of the start of exercise and persisted until two minutes into recovery. 

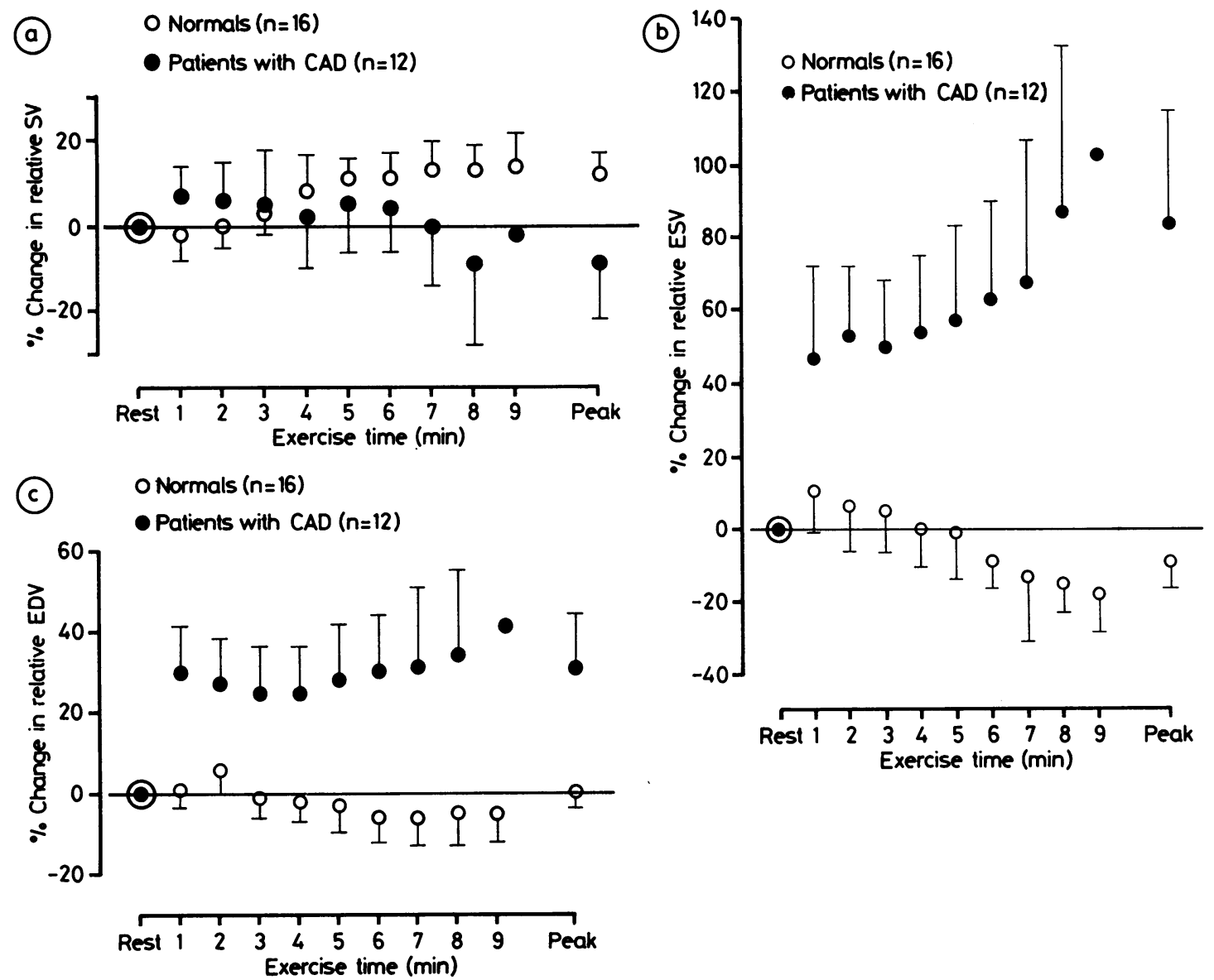

Fig. 5 Mean per cent change relative to rest each minute during supine cycle ergometry for (a) stroke volume (SV), (b) end systolic volume (ESV), and (c) end diastolic volume (EDV). Symbols as in Fig. 4. CAD, coronary artery disease.

resting and peak exercise ejection fraction values are shown for controls and patients in Fig. 2.

The mean ejection fraction of the 12 patients was $54.3 \%$ (range $46 \%-64 \%$ ) at rest and during exercise this decreased in all (mean $16.8 \%$, range $6 \%-25 \%$ ) (Fig. 3). In the controls the mean ejection fraction was $55.9 \%$ (range $47 \%-64 \%$ ) at rest and this increased during exercise in all (mean 10.2, range $3 \%-19 \%)$. The mean values of ejection fraction at rest and at each minute during exercise and recovery in both patients and controls are shown in Fig. 4. The ejection fraction fell in both groups during the first minute of exercise. The fall in the control group was not statistically significant and was reversed as exercise continued. The ejection fraction at one minute of exercise was significantly lower in the patient group than in the controls, and this difference was maintained throughout exercise and until 2 minutes into recovery. The ejection fraction fell by more than $5 \%$ absolute in all patients; in nine this fall occurred within the first minute of exercise and in seven within 30 seconds.

Fig. 5 shows the percentage change of the mean end diastolic, end systolic, and stroke volume each minute during exercise and at peak exercise relative to the resting values. The relative end diastolic and end systolic volumes of patients and controls diverged within the first minute of exercise whereas relative stroke volume did not differ until peak exercise, when the patients' stroke volume had decreased relative to that of the controls. Mean end diastolic volume changed little $(+0.5 \%$ relative to rest) in the normal controls (increased in nine, unchanged in three, decreased in four at peak exercise). Thus the increase $(+12 \%)$ of mean stroke volume (increased in 15, decreased in one subject) and ejection fraction was due to a decrease $(-9 \%)$ of end systolic volume (10 out of 16 subjects). By contrast both diastolic and 


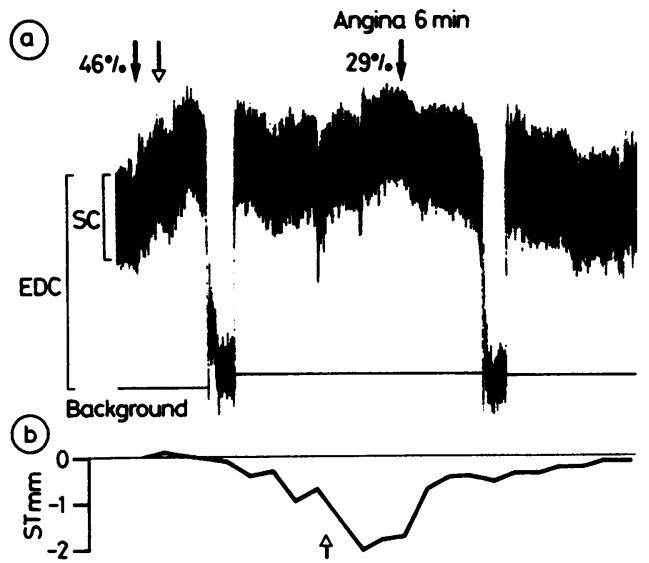

Fig. 6 Exercise test in a man of 63. (a) Time-activity curve (compressed form, paper speed $10 \mathrm{~mm}$ per minute) at rest, during exercise, and after exercise. The start and end of exercise are indicated by closed arrows and the per cent values are the ejection fraction at rest and peak exercise. The open arrow indicates when ejection fraction fell by $5 \%$ absolute. The probe was moved to background at rest, during the first stage of exercise, and during recovery. Blips are seen in the time-activity waveform when the patient coughed. (b) ST segment trend with the time of onset of $1 \mathrm{~mm}$ depression relative to the electrocardiogram at rest indicated by an open arrow. EDC, end diastolic counts; $S C$, stroke counts.

systolic volumes increased (mean increases $31 \%$ and $84 \%$ respectively) in all 12 patients at peak exercise, and mean stroke volume decreased slightly (mean fall $9 \%$; decreased in seven, unchanged in one, increased in four), resulting in pronounced reductions of ejection fraction in all.

In 11 of the 12 patients the ejection fraction had decreased by $5 \%$ absolute before the appearance of $1 \mathrm{~mm}$ ST segment depression (Fig. 1), including the one man who did not develop $1 \mathrm{~mm}$ ST depression at any time.

Background counts increased during exercise and then returned to the resting level during recovery in 10 of the 12 patients. The compressed record of the time-activity waveform of a representative patient is shown in Fig. 6 with the ST segment trend plotted below.

\section{Discussion}

The accuracy of the non-imaging nuclear probe for measuring left ventricular ejection fraction at rest is well established ${ }^{1314}$ and has been validated in our laboratory. ${ }^{15} \mathrm{We}$ have also compared the probe measurements of ejection fraction at peak semisupine cycle exercise with the results obtained with a digital gamma camera and we found good agreement be- tween the methods. ${ }^{11}$ The high count sensitivity of the probe permits beat to beat data acquisition and thus detection of rapidly occurring changes in left ventricular function. The maintenance of the probe over the left ventricular region of interest requires skill on the part of the operator, ${ }^{1214}$ particularly during dynamic exercise, ${ }^{11} 13$ but with experience continuous detection of left ventricular time-activity is possible even during maximal dynamic exercise. The stability of the exercising subject's chest was maintained in this study by careful attention to the seat position and the distance from the seat to the cycle pedals. The probe method is simpler than the first pass gold technique and avoids the need for repeated injections of an expensive radionuclide and the use of a digital or multicrystal gamma camera. It has the disadvantages, however, of not providing information about wall motion abnormalities and of requiring exercise to be performed in the supine or semisupine position. ${ }^{16}$

Previous studies have suggested that a few patients with coronary artery disease increase their ejection fraction during supine exercise whereas in many the ejection fraction does not change during exercise. ${ }^{4617}$ In all our patients the ejection fraction had fallen by at least $6 \%$ (absolute) at peak exercise. This difference can be explained by the selection criteria for our patients, all of whom had established angina and ST depression on treadmill exercise testing and most of whom had multivessel coronary artery disease. Higginbotham et al reported that a fall of ejection fraction during upright exercise identified a group of coronary patients with a high mortality during subsequent follow up. ${ }^{18}$

There was a consistent pattern of change of ejection fraction during exercise in our patients with coronary artery disease (Fig. 1). In nine of the 12 patients the ejection fraction decreased by at least $5 \%$ absolute within one minute of the start of exercise and in all but one this decrease became more pronounced as exercise progressed. In the remaining three patients the fall in ejection fraction was delayed until 3, 4, and 8.5 minutes of exercise. Even in these patients, however, a further decrease of ejection fraction occurred as exercise continued. Thus our results do not confirm the variability in the evolution of ejection fraction response to upright exercise observed by Wackers and coworkers ${ }^{7}$ or that noted by Brady et al in response to supine exercise. ${ }^{4}$ These workers found increases in ejection fraction during exercise in some patients; the relatively homogeneous response of our patients was probably the result of our selection criteria.

The initial fall of ejection fraction at the start of exercise in most of our patients is worthy of comment, particularly since there was a smaller and sta- 
tistically non-significant fall in the controls (Fig. 4). This is probably related to the inevitable isometric component inherent in the start of semisupine cycle exercise. Isometric exercise has been shown to induce a fall in ejection fraction in normal subjects ${ }^{19}$ as well as patients with coronary artery disease ${ }^{20} \mathrm{Sec}$ ondly the increase in venous return which occurs at the onset of dynamic exercise is greater and therefore causes a more pronounced rise in end diastolic volume in the supine position. The fact that other workers have not reported a decrease of ejection fraction during supine exercise in normal subjects may be due to their not recording ejection fraction during the first minute of exercise, since this can be done only with the non-imaging nuclear probe; the ejection fraction at the first minute of upright exercise has been measured by the gold- $195 \mathrm{~m}$ first pass technique. ${ }^{7}$

The fact that the ejection fraction of patients with coronary artery disease was significantly less than that of the controls after only one minute of exercise suggests that the difference could be due to the early onset of ischaemia, probably caused by the sudden increase in afterload that results from the isometric component inherent in ergometric exercise. The rise in left ventricular end diastolic pressure at the start of exercise in patients with ischaemic heart disease is well documented ${ }^{21}$ and supports the suggestion that the rapid deterioration of left ventricular function in patients as compared with controls may be related to myocardial ischaemia.

The observation that left ventricular dysfunction due to myocardial ischaemia can occur in the absence of, or before, the appearance of electrocardiographic changes has been made both by invasive $e^{1-3}$ and noninvasive means. ${ }^{22} 23$ Theroux et al showed that impairment of canine myocardial contractility, as measured by microsonometers implanted in the myocardium, could be detected within 15 seconds of ligating the coronary artery supplying that area of myocardium. ${ }^{24}$ Similar observations were made by Battler et al. ${ }^{3}$ Upton et al demonstrated a reduction in ejection fraction by first pass radionuclide angiography that was detectable during submaximal upright exercise before the appearance of ST segment depression in 19 of 25 patients who resembled those in the present study. ${ }^{22}$ Using exercise $M$ mode and cross sectional echocardiography, Sugishita et al obtained similar results from patients performing supine cycle ergometry ${ }^{23}$; however, the reproducibility of exercise echocardiography is questionable.

The decrease of ejection fraction with exercise in the patients was due to a large increase in relative end systolic volume $(+84 \%$ relative to rest). Relative end diastolic volume also increased but only modestly $(+31 \%)$. Findings in previous studies of changes in left ventricular volumes during supine exercise in patients with angina by contrast and radionuclide ventriculography were similar, with small decreases in stroke volume, small or no increase in end diastolic volume, and pronounced increases in end systolic volume. ${ }^{21} 2526$ Lahiri et al measured left ventricular end diastolic pressure and beat to beat ejection fraction with the nuclear probe during atrial stress pacing in patients with coronary artery disease, and they concluded that the fall in ejection fraction and increase in end diastolic pressure were closely related. ${ }^{11}$

The method of evaluating left ventricular function by the non-imaging nuclear probe gives information not available by any other non-invasive means. Further improvement in this technology ${ }^{1527}$ may lead to a better understanding of the underlying mechanisms of both induced and spontaneous myocardial ischaemia. Further study is required to determine whether the observed rapid fall in ejection fraction in this selected group of patients is truly due to myocardial ischaemia or due to an isometric component inherent in the exercise protocol, whether it is reproducible, and what the underlying haemodynamic alterations may be. These results, however, suggest that impairment of left ventricular function is a more sensitive indicator of myocardial ischaemia than electrocardiographic changes.

We thank Mr John Crawley and Mr David Hinge for valuable assistance.

\section{References}

1 Scheuer J, Brachfeld N. Coronary insufficiency: relations between haemodynamic, electrical and biochemical parameters. Circ Res 1966; 18: 178-89.

2 Waters DD, da Luz P, Wyatt HL, Swan HJC, Forrester JS. Early changes in regional and global left ventricular function induced by graded reductions in regional coronary perfusion. Am $\mathcal{F}$ Cardiol 1977; 39: 537-43.

3 Battler A, Froelicher VF, Gallagher KP, Kemper WS, Ross J Jr. Dissociation between regional myocardial dysfunction and ECG changes during ischaemia in the conscious dog. Circulation 1980; 62: 735-44.

4 Brady TJ, Thrall JH, Clare JM, Rogers WL, Lo K, Pitt B. Exercise radionuclide ventriculography: practical considerations and sensitivity of coronary artery disease detection. Radiology 1979; 132: 697-702.

5 Sorensen SG, Ritchie JL, Caldwell JH, Hamilton GW, Kennedy JW. Serial exercise radionuclide angiography. Validation of count-derived changes in cardiac output and quantitation of maximal exercise ventricular volume changes after nitroglycerin and propranolol in normal men. Circulation 1980; 61: 600-9.

6 Caldwell JH, Hamilton GW, Sorensen SG, Ritchie JL, Williams DL, Kennedy JW. The detection of coronary 
artery disease with radionuclide techniques: a comparison of rest-exercise thallium imaging and ejection fraction response. Circulation 1980; 61: 610-9.

7 Wackers FJT, Stein R, Pytlik L, et al. Gold-195m for serial first pass radionuclide angiocardiography during upright exercise in patients with coronary artery disease. F Am Coll Cardiol 1983; 2: 497-505.

8 Christopher TD, Konstantinov G, Jones RH. Bayesian analysis of data from radionuclide angiocardiograms for diagnosis of coronary artery disease. Circulation 1984; 69: 65-72.

9 Schneider J, Berger HJ, Sands MJ, Lachman AB, Zaret BL. Beat-to-beat left ventricular performance in atrial fibrillation: radionuclide assessment with the computerized nuclear probe. Am F Cardiol 1983; 51: 1189-95.

10 Giles RW, Berger HJ, Barash PG, et al. Continuous monitoring of left ventricular performance with the computerised nuclear probe during laryngoscopy and intubation before coronary artery bypass surgery. $A m \mathcal{F}$ Cardiol 1982; 50: 735-41.

11 Lahiri A, Bowles MJ, Jones RI, Crawley JCW, Raftery EB. Assessment of left ventricular function in coronary artery disease with the nuclear probe during intervention studies. Br Heart $\mathcal{F}$ 1984; 52: 422-30.

12 Wagner HN Jr, Wake R, Nickoloff E, Natarajan TK. The nuclear stethoscope: a simple device for generation of left ventricular volume curves. Am $\mathcal{F}$ Cardiol 1976; 38: 747-50.

13 Wagner HN Jr, Rigo P, Baxter RH. Monitoring ventricular function at rest and during exercise with a nonimaging nuclear detector. Am $\mathcal{f}$ Cardiol 1979; 43: 975-9.

14 Shen WF, Singer I, Hackworthy RA, Morris J, Kelly DT. The nuclear stethoscope. Serial evaluation of left ventricular function in patients with cardiac disease. Med F Aust 1983; i: 467-70.

15 Lahiri A, Crawley JCW, Jones RI, Bowles MJ, Raftery EB. A non-invasive technique for continuous monitoring of left ventricular function using a new solid state mercuric iodide radiation detector. Clin Sci 1984; 66: 551-6.

16 Appel M, Blumfield D. Reproducibility of supine exercise-testing [Letter]. Circulation 1981; 63: 469-70.

17 Osbakken MD, Boucher CA, Okada RO, Bingham JB, Strauss HW, Pohost GM. Spectrum of global left ventricular responses to supine exercise. Limitation in the use of ejection fraction in identifying patients with coronary artery disease. Am $\mathcal{f}$ Cardiol 1983; 51: 28-35.

18 Higginbotham MB, Coleman RE, Jones RH, Cobb FR. Mechanism and significance of a decrease in ejection fraction during exercise in patients with coronary artery disease and left ventricular dysfunction at rest. $\mathcal{f} \mathrm{Am}$ Coll Cardiol 1984; 3: 88-97.

19 Jones RI, Lahiri A, Cashman PMM, Dore C, Crawley JCW, Raftery EB. Continuous measurement of left ventricular ejection fraction during isometric handgrip and cold stress in normal subjects. An assessment of response and reproducibility [Abstract]. Clin Sci 1984; 66: $27 \mathrm{P}$

20 Giles R, Marx P, Comerford P, Zaret B, Berger H. Rapid sequential changes in left ventricular function during cold pressor and isometric handgrip: relationship to blood pressure and mechanistic implications [Abstract]. Am F Cardiol 1982; 49: 1002.

21 Lichtlen P. The haemodynamics of clinical ischemic heart disease. Ann Clin Res 1970; 3: 333-43.

22 Upton MT, Rerych SK, Newman GE, Port S, Cobb FR, Jones RH. Detecting abnormalities in left ventricular function during exercise before angina and STsegment depression. Circulation 1980; 62: 341-9.

23 Sugishita Y, Koseki S, Matsuda M, Tamura T, Yamaguchi I, Ito I. Dissociation between regional myocardial dysfunction and ECG changes during myocardial ischaemia induced by exercise in patients with angina pectoris. Am Heart $\mathcal{F} 1983$; $106: 1-8$.

24 Theroux P, Franklin D, Ross J Jr, Kemper WS. Regional myocardial function during acute coronary artery occlusion and its modification by pharmacologic agents in the dog. Circ Res 1974; 35: 896-908.

25 Sharma B, Goodwin JF, Raphael MJ, Steiner RE, Rainbow RG, Taylor SH. Left ventricular angiography on exercise: a new method of assessing left ventricular function in ischaemic heart disease. Br Heart $\mathcal{F} 1976$; 38: 59-70.

26 Slutsky R, Karliner J, Ricci D, et al. Response of left ventricular volume to exercise in man assessed by radionuclide equilibrium angiography. Circulation 1979; 60: 565-71.

27 Lahiri A, Crawley JCW, Hinge D, Cashman PMM, Raftery EB. A NaI-Photodiode for beat-to-beat left ventricular ejection fraction measurement [Abstract]. Clin Sci 1985;69: IP. 